\title{
Biliary Sphincterotomy Alone versus Biliary Stent with or without Biliary Sphincterotomy for the Management of Post-Cholecystectomy Bile Leak: A Systematic Review and Meta-Analysis
}

\author{
Navroop Nagra ${ }^{a}$ Jagpal Singh Klair ${ }^{a}$ Mahendran Jayaraj ${ }^{b}$ Arvind R. Murali ${ }^{c}$ \\ Dhruv Singh $^{d}$ Joanna Law ${ }^{a}$ Michael Larsen $^{a}$ Shayan Irani ${ }^{a}$ Richard Kozarek ${ }^{a}$ \\ Andrew Ross $^{\text {a }}$ Rajesh Krishnamoorthi ${ }^{\mathrm{a}}$ \\ aDigestive Disease Institute, Virginia Mason Medical Center, Seattle, WA, USA; bivision of Gastroenterology and \\ Hepatology, University of Nevada School of Medicine, Las Vegas, NV, USA; 'Division of Gastroenterology and \\ Hepatology, University of lowa Hospitals and Clinics, lowa, IA, USA; ${ }^{d}$ Division of Gastroenterology and Hepatology, \\ Mayo Clinic, Rochester, MN, USA
}

\section{Keywords}

Bile leak · Biliary stent · Endoscopic sphincterotomy ·

Post-cholecystectomy

\begin{abstract}
Background: Endoscopic therapy with endoscopic retrograde cholangiopancreatography is considered the first-line treatment in the management of post-cholecystectomy bile leak (PCBL). Currently, there is no consensus on the most effective endoscopic intervention for PCBL. Hence, we performed a systematic review and meta-analysis to compare the effectiveness and safety of the two interventional groups (biliary sphincterotomy [BS] alone vs. biliary stent \pm BS) in management of PCBL. Methods: We conducted a comprehensive search of multiple electronic databases and conference proceedings (from inception through January 2021). The primary outcome was to compare the pooled rate of clinical success between the 2 groups. The secondary outcome was to estimate the pooled rate of adverse events. $\boldsymbol{R e}$ sults: The pooled rate of clinical success with BS alone (5 studies, 299 patients) was $88 \%$ (95\% confidence interval $(\mathrm{Cl})$ : 84-92\%, I²: 0\%) and for biliary stent \pm BS (5 studies, 864 pa-
\end{abstract}

Karger@karger.com

(c) 2022 S. Karger AG, Basel

www.karger.com/ddi

Karger! tients) was $97 \%$ (Cl: 93-100\%, I2: 79\%). The rate of clinical success in biliary stent \pm BS group was significantly higher than BS alone group (OR: 3.91 95\% Cl: 2.29-6.69, $p<0.001$, $\left.1^{2}: 13 \%\right)$. The rate of adverse events was numerically lower in biliary stent \pm BS group compared to BS alone (3 studies; OR: 0.65 95\% Cl: $0.41-1.03, p=0.07$ ) without statistical significance. Low heterogeneity was noted in the analysis. Conclusions: Biliary stent \pm BS is more effective in endoscopic management of PCBL compared to BS alone. This may be related to inter-endoscopist variation in completeness of sphincterotomy and post-sphincterotomy edema, which can influence the preferential trans-papillary flow of bile.

(c) 2022 S. Karger AG, Basel

\section{Introduction}

Laparoscopic cholecystectomy is one of the most common abdominal surgeries performed in the USA. While minor bile leaks can resolve without any intervention, clinically significant bile leaks occur in $0.8-1.1 \%$ of pa-

Navroop Nagra and Jagpal Singh Klair share co-first authorship. 
tients, which warrants some form of intervention for resolution [1-4]. In cases of bile leak, the cystic duct remnant is the most common site for bile leak followed by injuries to the ducts within the gallbladder bed, common bile duct, common hepatic duct, and T-tube tracts [5]. Diagnosis of bile leak can often be made on imaging studies; however, imaging cannot rule out the diagnosis when the clinical suspicion is high. Endoscopic retrograde cholangiopancreatography (ERCP) has diagnostic and therapeutic roles in such cases [5-7].

The various interventions available to manage bile leak include surgical repair, percutaneous drainage, endoscopic drainage, or a combination of these. ERCP is the first-line treatment for the management of post-cholecystectomy bile leak (PCBL) $[8,9]$. The goal of endoscopic therapy is to enable preferential trans-papillary flow of bile by equalizing the pressure in the bile duct and the duodenum. This can be achieved endoscopically by biliary sphincterotomy $(\mathrm{BS})$ alone or biliary stent $\pm \mathrm{BS}[8,10$, 11]. Currently, there is no consensus on the most effective endoscopic intervention for PCBL - BS alone versus biliary stent $\pm \mathrm{BS}$ and this leads to practice variations. Hence, we aimed to reliably estimate the pooled rate of effectiveness and safety of the two interventional groups (BS alone vs. biliary stent $\pm \mathrm{BS}$ ) in the management of PCBL through a systematic review and meta-analysis.

\section{Materials and Methods}

This systematic review was performed in accordance with the Cochrane Handbook for Systematic Reviews of Interventions [12]. It is reported in accordance with Preferred Reporting Items for Systematic Reviews and Meta-Analyses (PRISMA) guidelines [13].

\section{Data Sources and Searches}

We conducted a comprehensive search of several databases and conference proceedings, including PubMed, EMBASE, and Web of Science databases (earliest inception to January 2021) to identify studies that compared BS alone versus biliary stent \pm BS for management of PCBL. The literature search was performed by an experienced medical librarian using input from the study authors. The details of the search strategy and data sources are reported in online supplementary material 1 (for all online suppl. material, see www.karger.com/doi/10.1159/000522328).

Key words used in the search included a combination of postcholecystectomy, bile leak, ERCP, endoscopic sphincterotomy, and biliary stent. The search was restricted to studies with human subjects published in the English language. Two authors (N.N. and J.K.) independently reviewed the titles and abstracts of studies identified in the primary search and excluded studies that did not address the research question, based on prespecified exclusion and inclusion criteria. The full-text of remaining articles was reviewed to determine whether it contained relevant information. Any dis- crepancy in article selection was resolved by consensus and in discussion with the senior author (R.K.). The bibliographic sections of the selected articles, as well as other narrative review articles on the topic, were also manually searched for additional relevant articles.

\section{Selection Criteria}

In the meta-analysis, we included studies that met the following inclusion criteria: (1) studies on patients with PCBL which reported comparative data on outcomes with BS alone versus stent placement $\pm B S$, (2) reported the rates of clinical success, and (3) sample size of 10 patients or more. We excluded (1) studies that did not compare the two interventions (BS alone vs. stent placement \pm BS), (2) studies on bile leaks other than PCBL, and (3) letters to the editors. In case of multiple publications from the same cohort, data from the most recent and/or most appropriate comprehensive report were included.

\section{Data Abstraction and Quality Assessment}

After identifying relevant studies, data on the study characteristics, patient characteristics, and relevant study outcomes were abstracted onto a standardized form by 2 authors (N.N. and J.K.). The quality of the individual studies was independently assessed by 2 authors (N.N. and J.K.) using the Newcastle-Ottawa scale for cohort studies [14]. The quality scale consisted of 8 questions. Using the scale, the studies were assigned scores under 3 broad perspectives: (1) selection (4 questions), (2) comparability of study groups (1 question), and (3) ascertainment of the outcome of interest (3 questions). All questions received a score of 1 except for comparability which could get a maximum of 2 . Studies with a total score of $\geq 8,6-7$, and $\leq 5$ were considered suggestive of high quality, medium quality, and low quality, respectively. Any discrepancies in Data Abstraction and Quality Assessment were resolved by joint assessment of the original articles by 2 authors (N.N. and J.K.) [15].

\section{Outcome Assessed}

The primary outcome was to compare the pooled rate of clinical success between the 2 intervention groups - BS alone versus stent placement \pm BS. Clinical success was defined as the ability to manage the PCBL with endoscopic interventions alone without need for surgery. The secondary outcome was to compare the pooled rate of adverse events between the 2 intervention groups.

\section{Statistical Analysis}

Using the random-effects model described by DerSimonian and Laird [16], we calculated the pooled rates of clinical success, technical success, and adverse events and 95\% confidence intervals (CIs). Heterogeneity between study-specific estimates was assessed using the inconsistency index (I2 statistic), which estimates the proportion of total variation across studies that is related to heterogeneity rather than by chance. Values of $<30 \%, 30-60 \%, 61-$ $75 \%$, and $>75 \%$ were considered suggestive of low, moderate, substantial, and considerable heterogeneity, respectively [17]. If there were $\geq 10$ studies included in the meta-analysis, we planned to assess for publication bias qualitatively, by visual inspection of funnel plot and quantitatively, by the Egger test [14]. All statistical analyses were performed using Open Meta analyst (CEBM, Brown University, and Providence, RI, USA). 
Fig. 1. Flowchart summarizing study selec-

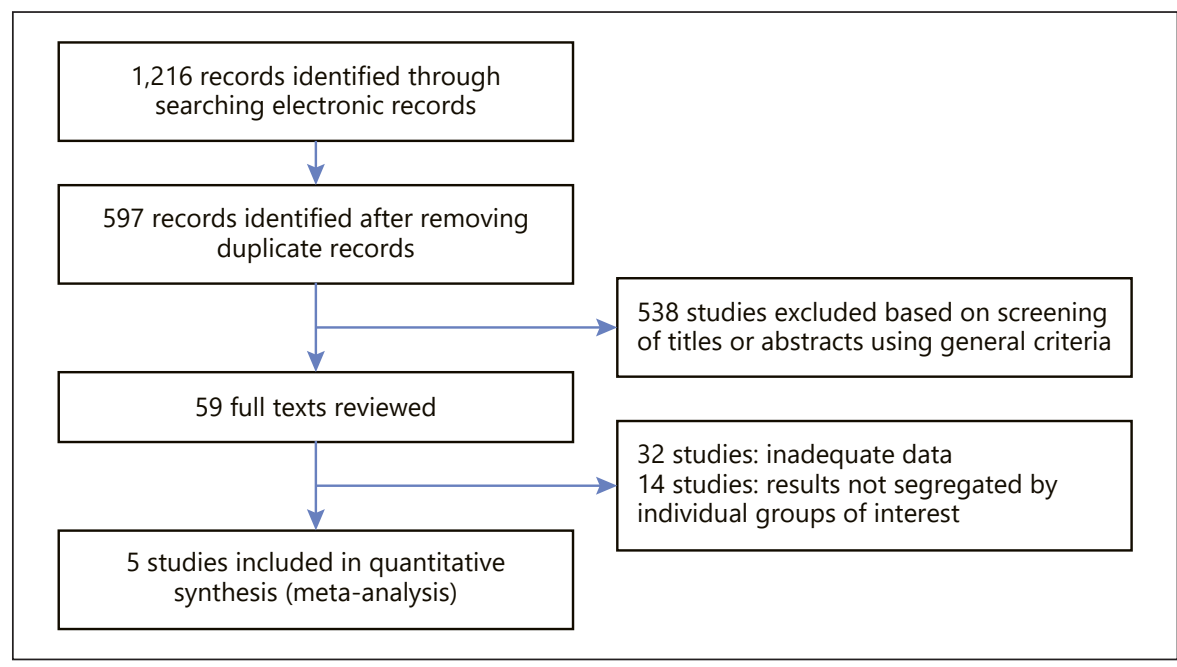
tion process.

Table 1. Study characteristics

\begin{tabular}{|c|c|c|c|c|c|c|c|c|}
\hline Abbas et al. [18] & USA & Retrospective & Multicenter & 228 & 224 & 480 & $52 / 48$ & 56 \\
\hline Chandra et al. [20] & USA & Retrospective & Single center & 35 & 0 & 17 & $32 / 68$ & 54 \\
\hline Dolay et al. [8] & Turkey & Prospective & Single center & 13 & 0 & 14 & $37 / 63$ & 52 \\
\hline Kaffes et al. [19] & Australia & Retrospective & Single center & 18 & 40 & 31 & $39 / 61$ & 53 \\
\hline Sachdev et al. [11] & India & Retrospective & Single center & 5 & 6 & 52 & NA & NA \\
\hline
\end{tabular}

Table 2. Outcome measures and quality of included studies

\begin{tabular}{|c|c|c|c|c|c|c|c|c|}
\hline $\begin{array}{l}\text { Study/year of } \\
\text { publication }\end{array}$ & $\begin{array}{l}\text { Sphincterotomy } \\
\text { alone success, } \\
\%(n / N)\end{array}$ & $\begin{array}{l}\text { Sphincterotomy } \\
\text { alone adverse } \\
\text { events, } \%(n / N)\end{array}$ & $\begin{array}{l}\text { Stent alone } \\
\text { success, \% } \\
(n / N)\end{array}$ & $\begin{array}{l}\text { Stent alone } \\
\text { adverse events, } \\
\%(n / N)\end{array}$ & $\begin{array}{l}\text { Stent and } \\
\text { sphincterotomy, } \\
\text { success, \% }(n / N)\end{array}$ & $\begin{array}{l}\text { Stent and } \\
\text { sphincterotomy, } \\
\text { adverse events, \% } \\
(n / N)\end{array}$ & $\begin{array}{l}\text { Death, \% } \\
(n / N)\end{array}$ & $\begin{array}{l}\text { Study } \\
\text { quality }\end{array}$ \\
\hline Abbas et al. [18] & $89(203 / 228)$ & $13(29 / 228)$ & $96(215 / 224)$ & $9(20 / 224)$ & $97(465 / 480)$ & $9(43 / 480)$ & 0 & 7 \\
\hline Chandra et al. [20] & $91(32 / 35)$ & 0 & NA & NA & $94(16 / 17)$ & 0 & 0 & 4 \\
\hline Dolay et al. [8] & $85(11 / 13)$ & 0 & NA & NA & $100(14 / 14)$ & 0 & 0 & 8 \\
\hline
\end{tabular}

\section{Results}

A total of 1,216 studies were identified by our search criteria. 597 studies were identified after removing duplicate records. After excluding 538 studies based on title and abstract review, 59 full-text articles were reviewed. Thirty-two studies were excluded due to inadequate data; 14 studies were excluded as the results were not segregated by interventional groups of interest; and 8 studies were excluded due to overlapping population.
We identified 5 comparative studies reporting outcomes of endoscopic management of PCBL (with BS alone vs. biliary stent \pm BS) that fulfilled our inclusion criteria and included them in the meta-analysis $[8,11$, 18-20]. The schematic diagram of study identification and selection is illustrated in Figure 1.

\section{Characteristics of Included Studies}

Study characteristics and quality of the included studies are summarized in Tables 1 and 2. Four studies were 


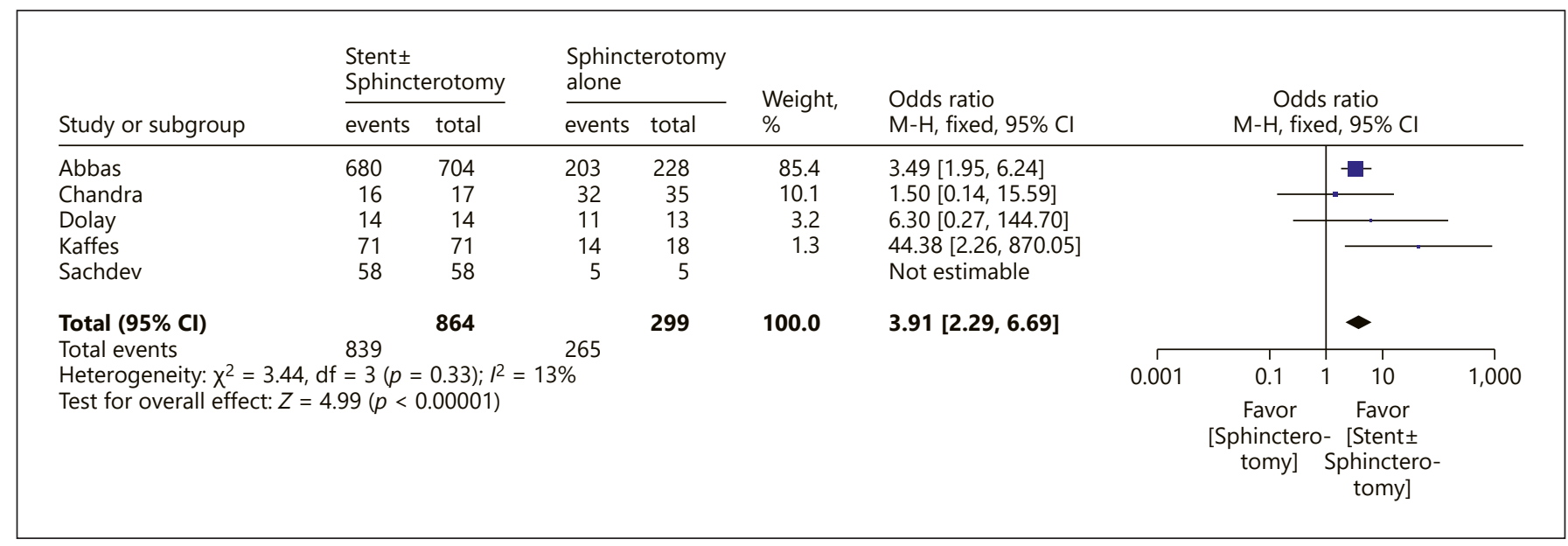

Fig. 2. Forest plot: success of sphincterotomy alone and stent \pm sphincterotomy for PCBL. Abbas et al. [18], Chandra et al. [20], Dolay et al. [8], Kaffes et al. [19], Sachdev et al. [11]. OR, odds ratio.

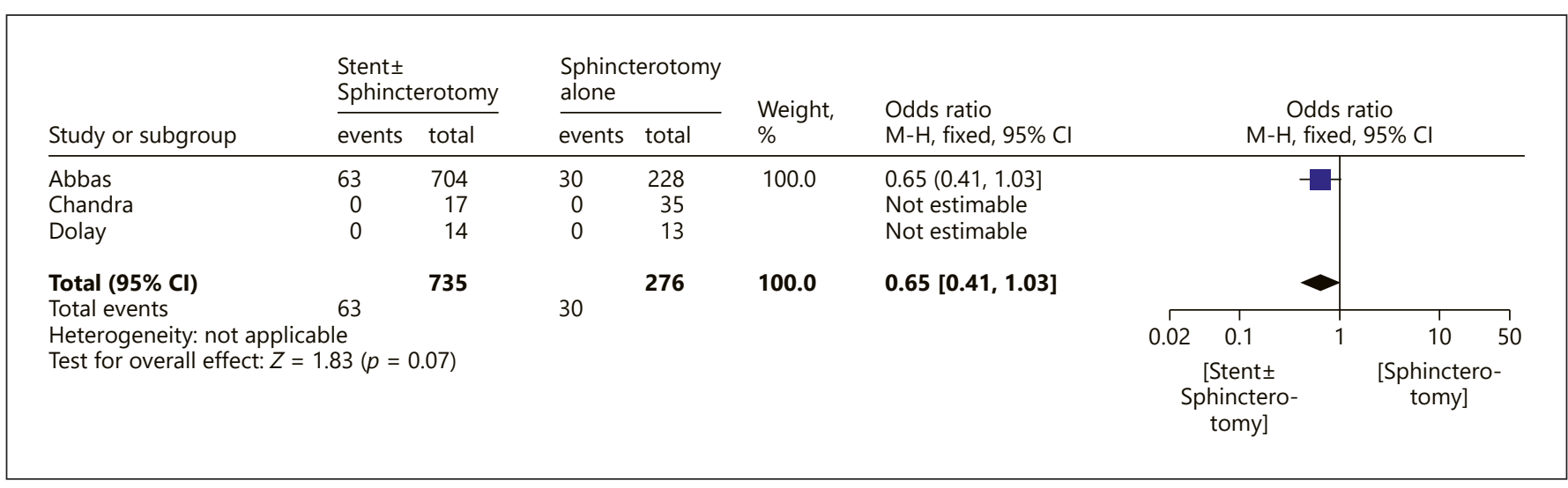

Fig. 3. Forest plot: adverse events related to sphincterotomy alone and stent \pm sphincterotomy for bile leak postcholecystectomy. Abbas et al. [18], Chandra et al. [20], Dolay et al. [8]. OR, odds ratio.

single-center studies, and one was a multicenter study. Four studies were published as manuscripts, and 1 study was published as an abstract. Four studies were retrospective in design, and 1 study was a prospective randomized study.

Online supplementary Table 1 summarizes the quality assessment of included studies. One study was deemed to be high quality. Three studies were deemed medium quality, and 1 study was deemed low quality [21].

\section{Outcomes}

Primary Outcome - Clinical Success

The 5 included studies reported a total of 299 patients who underwent BS alone and 864 patients who under- went biliary stent \pm BS. The pooled rate of clinical success with BS alone was $88 \%$ (95\% CI: 84-92\%, $\left.\mathrm{I}^{2}: 0 \%\right)$ and with biliary stent \pm BS was $97 \%$ (CI: $\left.93-100 \%, \mathrm{I}^{2}: 79 \%\right)$. The rate of clinical success in the biliary stent \pm BS group was significantly higher than that of the BS alone group (OR: $3.9195 \%$ CI: 2.29-6.69, $p<0.001, \mathrm{I}^{2}: 13 \%$ ) (Fig. 2).

\section{Secondary Outcome - Adverse Events}

Two of the 5 studies included in the pooled analysis of clinical success did not report adequate data on adverse effects. The 3 included studies reported a total of $276 \mathrm{pa}-$ tients who underwent BS alone and a total of 735 patients who underwent biliary stent \pm BS. The rate of adverse events was numerically lower in the biliary stent \pm BS 
group compared to BS alone (3 studies; OR: 0.65, 95\% CI: $0.41-1.03, p=0.07)$ without statistical significance (Fig. 3).

\section{Heterogeneity and Publication Bias}

In the pooled analysis of the primary outcome - clinical success of PCBL with BS alone versus biliary stent \pm BS, the heterogeneity $\left(I^{2}\right)$ was noted to be low $\left(I^{2}=13\right)$. Assessment for publication bias was not performed as there were $<10$ studies included in the analysis.

\section{Discussion}

Management of PCBL requires early diagnosis and appropriate intervention. Endoscopic management has a high success rate with lower rates of morbidity and mortality when compared to surgical repair [22-25]. Endoscopic interventions to manage PCBL include BS alone or biliary stent \pm BS [18]. The basic principle behind the use of both endoscopic interventions is to eliminate the pressure gradient between the bile duct and the duodenum which leads to flow of bile into the duodenum and helps in healing of injured bile ducts [26, 27]. Currently, there is no consensus on which endoscopic intervention should be used and this leads to practice variations. To our knowledge, this is the first systematic review and meta-analysis directly comparing the effectiveness of BS alone versus biliary stent placement \pm BS in the management of PCBL.

In the pooled analysis of five included studies, the pooled rate of clinical success with BS alone was $88 \%$ and biliary stent \pm BS was $97 \%$. The rate of clinical success in the biliary stent \pm BS group was significantly higher than in the BS alone group (OR: 3.91 95\% CI: 2.29-6.69, $p<$ $\left.0.001, \mathrm{I}^{2}: 13 \%\right)$. Only 3 out of 5 included studies reported the adverse effects. The rate of adverse events was numerically lower in the biliary stent \pm BS group compared to BS alone without statistical significance (OR: 0.65, 95\% CI: $0.41-1.03, p=0.07$ ).

The lower success rate in the BS alone group may be related to inter-endoscopist variation in completeness of sphincterotomy and post-sphincterotomy edema, which can influence the preferential trans-papillary flow of bile. $\mathrm{BS}$ is mostly required if there is retained common bile duct stone post-cholecystectomy. In the presence of retained stone, if the BL is low grade, then it can be managed by $\mathrm{BS}$ and stone extraction alone; however, biliary stent is mostly required in high grade leaks along with BS. The major disadvantage of stent placement is the need for repeat ERCP for the removal of biliary stent [28]. This leads to additional cost to the patient and reexposure to anesthesia. Other complications of stent placement are increased risk of cholangitis, migration of stent, biliary stricture, and pancreatitis. There is increased chance of lost to follow-up when it comes to stent removal, as once patients feel better, they might not want to go through repeat ERCP, and this can lead to increased chances of infections and other complications.

The major strength of the current meta-analysis is that we only included studies which reported direct comparative data between BS alone versus biliary stent \pm BS in endoscopic management of PCBL. The other strengths include comprehensive and systematic literature search of multiple databases; strict well-defined inclusion and exclusion criteria; careful avoidance of redundant studies; and a detailed quality assessment.

The current meta-analysis has several limitations. There were a limited number of comparative studies which directly compared the outcomes of BS alone versus biliary stent \pm BS in endoscopic management of PCBL. Four of the five included studies were retrospective studies. Comparative data on adverse effects were not reported in only three of the five included studies, which makes our estimates less reliable. In addition, the studies reported inadequate data on specific types of adverse events like post-ERCP pancreatitis to enable additional pooled analyses on specific types of adverse events. Individual studies did not report data comparing the success of endoscopic management based on the site of bile leak, though the most common site of leak was at the cystic duct remnant. It must be noted that the individual studies excluded patients with complete transection of major bile ducts. The low heterogeneity noted in the analysis should be interpreted with caution given the small number of studies included in the meta-analysis.

In conclusion, based on our meta-analysis of studies comparing the effectiveness of BS alone versus biliary stent placement \pm BS in endoscopic management of PCBL, biliary stent \pm BS is more effective than BS alone. While the rate of adverse events was numerically lower in the biliary stent \pm BS group, they were statistically similar in the two approaches. Hence, ERCP with stent placement \pm BS should be the preferred approach for endoscopic management of PCBL despite the need for an additional endoscopic procedure to remove the biliary stent.

\section{Statement of Ethics}

An ethics statement was not required for this study type, no human or animal subjects were used. 


\section{Conflict of Interest Statement}

The authors have no conflicts of interest or financial ties to disclose.

\section{Funding Sources}

No funding was obtained for this study.

\section{Author Contributions}

Navroop Nagra - data acquisition and statistical analysis, drafting of manuscript. Jagpal Singh Klair - manuscript inception, data acquisition and statistical analysis, drafting of manuscript. Mahen- dran Jayaraj - manuscript inception, drafting of manuscript. Arvind R. Murali - data acquisition and statistical analysis, critical revision, and final approval. Dhruv Singh - data acquisition and statistical analysis. Joanna Law - critical revision and final approval. Michael Larsen - critical revision and final approval. Shayan Irani - critical revision and final approval. Richard Kozarek - critical revision and final approval. Andrew Ross - critical revision and final approval. Rajesh Krishnamoorthi - manuscript inception, data acquisition and statistical analysis, critical revision, and final approval.

\section{Data Availability Statement}

The authors confirm that the data supporting the findings of this study are available within the article and its online supplementary materials.

\section{References}

1 Barkun AN, Rezieg M, Mehta SN, Pavone E, Landry S, Barkun JS, et al. Postcholecystectomy biliary leaks in the laparoscopic era: risk factors, presentation, and management. McGill Gallstone Treatment Group. Gastrointest Endosc. 1997;45(3):277-82.

2 Csikesz NG, Singla A, Murphy MM, Tseng JF, Shah SA. Surgeon volume metrics in laparoscopic cholecystectomy. Dig Dis Sci. 2010; 55(8):2398-405.

3 Khan MH, Howard TJ, Fogel EL, Sherman S, McHenry L, Watkins JL, et al. Frequency of biliary complications after laparoscopic cholecystectomy detected by ERCP: experience at a large tertiary referral center. Gastrointest Endosc. 2007;65(2):247-52.

4 Trondsen E, Ruud TE, Nilsen BH, Marvik R, Myrvold HE, Buanes T, et al. Complications during the introduction of laparoscopic cholecystectomy in Norway. A prospective multicentre study in seven hospitals. Eur J Surg. 1994;160(3):145-51.

5 Sandha GS, Bourke MJ, Haber GB, Kortan PP. Endoscopic therapy for bile leak based on a new classification: results in 207 patients. Gastrointest Endosc. 2004;60(4):567-74.

6 Bergman JJ, van den Brink GR, Rauws EA, de Wit L, Obertop H, Huibregtse K, et al. Treatment of bile duct lesions after laparoscopic cholecystectomy. Gut. 1996;38(1):141-7.

7 Rustagi T, Aslanian HR. Endoscopic management of biliary leaks after laparoscopic cholecystectomy. J Clin Gastroenterol. 2014;48(8): 674-8.

8 Dolay K, Soylu A, Aygun E. The role of ERCP in the management of bile leakage: endoscopic sphincterotomy versus biliary stenting. J Laparoendosc Adv Surg Tech A. 2010;20(5): 455-9.

9 Navaneethan U, Jayanthi V. Endoscopic management of biliary leaks. The answer for the future. Minerva Gastroenterol Dietol. 2008;54(2):141-50.
10 Christos Mavrogiannisa CL, Ioannis S, Papanikolaoua B, Karagiannisa S, Galanisa P, Romanosc A. Biliary stenting alone versus biliary stenting plus sphincterotomy for the treatment of post-laparoscopic cholecystectomy biliary leaks: a prospective randomized study. Eur J Gastroenterol Hepatol. 2006; 18(4):405-9.

11 Sachdev A, Kashyap JR, D'Cruz S, Kohli DR, Singh R, Singh K. Safety and efficacy of therapeutic endoscopic interventions in the management of biliary leak. Indian J Gastroenterol. 2012;31(5):253-7.

12 Higgins J, Green S. Cochrane handbook of systematic reviews of interventions version 5.1.0. 2011.

13 Moher D, Liberati A, Tetzlaff J, Altman DG, Group P. Preferred reporting items for systematic reviews and meta-analyses: the PRISMA statement. BMJ. 2009; 339(4) b2535W64-9.

14 Easterbrook PJ, Berlin JA, Gopalan R, Matthews DR. Publication bias in clinical research. Lancet. 1991;337(8746):867-72.

15 Stang A. Critical evaluation of the NewcastleOttawa scale for the assessment of the quality of nonrandomized studies in meta-analyses. Eur J Epidemiol. 2010;25(9):603-5.

16 DerSimonian R, Laird N. Meta-analysis in clinical trials. Control Clin Trials. 1986;7(3): 177-88.

17 Guyatt GH, Oxman AD, Kunz R, Woodcock J, Brozek J, Helfand M, et al. GRADE guidelines: 7. Rating the quality of evidence - inconsistency. J Clin Epidemiol. 2011;64(12): 1294-302.

18 Abbas A, Sethi S, Brady P, Taunk P. Endoscopic management of postcholecystectomy biliary leak: when and how? a nationwide study. Gastrointest Endosc. 2019;90(2):2331.
19 Kaffes AJ, Hourigan L, De Luca N, Byth K, Williams SJ, Bourke MJ. Impact of endoscopic intervention in 100 patients with suspected postcholecystectomy bile leak. Gastrointest Endosc. 2005;61(2):269-75.

20 Chandra S, Murali AR, Masadeh M, Silverman WB, Johlin FC. Comparison of biliary stent versus biliary sphincterotomy alone in the treatment of bile leak. Dig Dis. 2020;38(1):32-7.

21 Engels EA, Schmid CH, Terrin N, Olkin I, Lau $J$. Heterogeneity and statistical significance in meta-analysis: an empirical study of 125 meta-analyses. Stat Med. 2000;19(13):1707-28.

22 Browder IW, Dowling JB, Koontz KK, Litwin MS. Early management of operative injuries of the extrahepatic biliary tract. Ann Surg. 1987;205(6):649-58.

23 Soper NJ, Flye MW, Brunt LM, Stockmann PT, Sicard GA, Picus D, et al. Diagnosis and management of biliary complications of laparoscopic cholecystectomy. Am J Surg. 1993;165(6):663-9.

24 Sauerbruch T, Weinzierl M, Holl J, Pratschke E. Treatment of postoperative bile fistulas by internal endoscopic biliary drainage. Gastroenterology. 1986;90(6):1998-2003.

25 Smith AC, Schapiro RH, Kelsey PB, Warshaw AL. Successful treatment of nonhealing biliary-cutaneous fistulas with biliary stents. Gastroenterology. 1986;90(3):764-9.

26 Katsinelos P, Paroutoglou G, Beltsis A, Tsolkas P, Arvaniti M, Katsiba D, et al. Endobiliary endoprosthesis without sphincterotomy for the treatment of biliary leakage. Surg Endosc. 2004;18(1):165-6.

27 Neidich R, Soper N, Edmundowicz S, Chokshi H, Aliperti G. Endoscopic management of bile duct leaks after attempted laparoscopic cholecystectomy. Surg Laparosc Endosc. 1996;6(5):348-54.

28 Coelho-Prabhu N, Baron TH. Assessment of need for repeat ERCP during biliary stent removal after clinical resolution of postcholecystectomy bile leak. Am J Gastroenterol. 2010;105(1):100-5. 